\title{
EVALUAR POR COMPETENCIA O COMO POTENCIA. UNA MIRADA REFLEXIVA Y CRÍTICA.
}

Evaluate by competition or like power. A reflexive and critical look.

\author{
Josefa Zabala de Alemán* y José Sánchez Carreño**
}

\section{RESUMEN}

Desde la racionalidad crítica han emergido nuevos modos de pensamiento sobre la teoría y práctica evaluativa con sentido de lo sociocontextual y humano, propiciando la recuperación del sujeto sociohistórico y cultural requerido para el desarrollo de las comunidades. Por ello, el objetivo de este trabajo es develar las bases constitutivas de la evaluación por competencia, desvinculada de lo subjetivo para avizorar una noción otra como potencia. Para ello, se utilizó la hermenéutica crítica, como camino metodológico para adentrarnos en la realidad evaluativa, mostrando dos aristas posibles de su quehacer: la cosificación del sujeto educativo o su emancipación. En tal sentido las ideas de Freire (2006), Foucault (1990), Deleuze y Guattari (1999), sirven de sustento para proponer una evaluación como potencia del ser humano más humano, quien al empoderarse de su subjetividad, re-invente la realidad en colectivo como expresión de lo intersubjetivo. Es decir, una evaluación de lo sensible, lo creativo y lo autónomo, intrínseco en la formación, la cual resurgirá como potenciación emancipadora y vitalista de la praxis pedagógica, desde una ontología otra de su hacer. En suma, las actuales demandas socioeducativas conminan a una nueva ontoepistemología de la evaluación para la transformación emancipadora del ser de la educación. Para ello, tenemos que deslastrarnos de nociones y prácticas tecnicoinstrumentales, así trazar nuevas líneas de fuga en su acontecer, constituyéndola en un espacio para la potenciación de lo humano.

Palabras clave: Evaluación, Intersubjetividad, Formación, Potencia.

RECIBIDO: Marzo 2019

ACEPTADO: Junio 2019

\footnotetext{
* Doctora en Educación. Universidad de Oriente. Núcleo de Sucre. Cumana, Venezuela. Correo electrónico: zabajo@hotmail.com

** Doctor en Educación. Universidad de Oriente. Rectorado. Cumaná, Venezuela. Correo electrónico: jsanchezc239@gmail.com Google académico: https://scholar.google.es/citations?user=IBpfebYAAAAJ\&hl=es
} 


\begin{abstract}
From critical rationality, new ways of thinking about theory and evaluative practice have emerged with a sense of the contextual partner and human, propitiating the sociohistorical and cultural subject recovery that it is required to communities' development. Therefore, this paper has as objective to reveal the constitutive bases of the evaluation by competence, detached from the subjective to envision another notion like power. For this, critical hermeneutics was used as a methodological way to get into the evaluative reality, showing two possible edges of its task: the objectification of the educational subject or its emancipation. In this sense, the ideas of Freire (2006), Foucault (1990), Deleuze and Guattari (1999), served as support to propose an evaluation like powering of the most human human being, who by empowering himself of his subjectivity, he re-invents reality in collective as an intersubjective expression .That is to say, an evaluation of the sensitive, the creative and the autonomous, intrinsic in the formation, which will resurface as emancipatory and vitalist empowerment of the pedagogical praxis, from an ontology another of its doing. In sum, current socioeducational demands lead to a new ontoepistemology of evaluation in order to emancipate transformation of being of education. To do this, we have to get rid of technical and instrumental notions and practices, thus drawing new leakage lines in their events, constituting it in a space for the empowerment of the human.
\end{abstract}

Key words: Evaluation, Intersubjectivity, Training, Power.

\title{
Introducción
}

El mundo contemporáneo está sumergido entre corrientes de pensamientos, cuyos fundamentos epistemológicos, filosóficos y axiológicos son adversos o están mezclados; imponiéndole al hombre de hoy una connotación de vida más dinámica, de desafíos y retos según sus modos de ver, pensar y actuar. Estos modos o visiones de pensamiento conforman un sistema de reglas o principios, orientadores de la dinámica de relaciones políticas, económicas, científicas, tecnológicas, sociales, culturales y educativas en toda sociedad, dando así la posibilidad de replantear la manera como nos aproximamos a la realidad circundante.

Las sociedades a través del tiempo han asumido diferentes posturas paradigmáticas en función de la concepción de hombre y mundo imperante; cuya orientación política ideológica establece el cómo “debe ser" las relaciones y producciones, de las diferentes esferas sociales. Legado transmitido de una generación 
Evaluar por competencia o como potencia. Una mirada reflexiva y crítica.

a otra, por la antigua civilización griega, la cual dio la pauta para la estructura y organización de los grupos societales en el mundo actual.

Fundamentándose, entonces, en la necesidad de una visión filosófica, antropológica y ontológica del hombre, surge a partir del Siglo XVIII la Modernidad como única forma de pensamiento, la cual hizo ruptura con toda noción mítica, religiosa y subliminal sobre la vida y el mundo. Ésta, afianzándose en el paradigma positivista, cambió los estándares de vida humana en lo filosófico, lo intelectual, lo literario, lo estético, lo económico, lo político, lo social, lo cultural y lo educativo.

A partir de ese momento, desde la ciencia positiva surgió una noción de realidad, asumida como verdad absoluta; desechando posicionamientos opuestos a sus principios de racionalidad y objetividad. Cuyos signos de enclave, nociones y principios reguladores y/u ordenadores, de cómo se accede y se produce el conocimiento, dieron lugar al desarrollo de la ciencia y la técnica como instrumentos para el progreso de las sociedades, bajo la promesa de una supuesta igualdad de oportunidades. De igual forma, esta episteme moderna mantuvo un modo de vida racionalista y materialista; que, en vez de liberar al hombre, lo ha deshumanizado llevándolo a un término de no reconocerse como ser capaz de trans-formar-se y liberar-se. Desde hace tres siglos el mundo moderno ha operado, imponiendo un modo de vida técnico e instrumental para la alienación del hombre y para el mantenimiento de una forma de pensamiento racional.

Al respecto Damiani (2009) expone:

El conocimiento científico, única forma de conocimiento válido, no puede invertir el tiempo y energía fantaseando sobre la esencia de los fenómenos; su función, por el contrario, es investigar las leyes de los mismos y sobre esta base perfeccionar el dominio del hombre sobre el mundo, porque, según Compte, una civilización se caracteriza básicamente por el nivel de cientificidad alcanzado en ella, dicho en otras palabras, son los logros, los alcances de tipo intelectual, lo que caracterizan toda época histórica (p. 138).

En nombre del desarrollo científico-técnico, el ser humano fue convertido en una máquina racional para el control y manipulación de todo los ámbitos y esferas sociales, 
lo cual conllevó a un supuesto progreso. Este ideal de vida, característica de las sociedades modernas, trajo consigo la concepción de educación, como medio de capacitación del ciudadano requerido por una nación para su desarrollo y evolución, regida por un paradigma pedagógico instrumentalista del hacer educativo. Entendido así, lo pedagógico pasó a estar orientado por la racionalidad tecnoinstrumental. Ésta por su rigidez, objetividad y fragmentación, ha obstaculizado la potencialidad reflexiva en el ser de la educación.

La modernidad, a través de la técnica y la ciencia, impone un saber racional como hilo conductor de toda trama de relaciones culturales; siendo la evaluación uno de los instrumentos más idóneos que, en el contexto escolar, es utilizado para el afianzamiento de formas de relaciones, valores, costumbres y conocimiento, como medio de control ideológico de los grupos sociales. Es así como, ésta programa, organiza y vigila el mundo de los individuos; transmitiéndoles normas, reglas y saberes cosificados y preconfigurados bajo la consigna futurista de "una educación de la eficiencia para el continuo progreso humano".

La epistemología de la evaluación que, desde la modernidad, impera en los contextos educativos, es el arquetipo de un modo de producción de conocimientos basado en la memorización (reproducción de saberes), el cual privilegia a algunos y excluye a otros, decide las formas de organización y difusión del saber, establece formas de jerarquización y promoción de los grupos de individuos e interviene en la configuración de las prácticas y de las instituciones escolares. Todo ello en función de reproducir modos de relaciones, valores y leyes sociales estructuralmente constituidas como relaciones de dominación (Téllez, 1998).

La función de esta visión administrativo-instrumental del saber- su taxonomía, en palabras de Foucault (1990) - permitió la acumulación de una cultura especializada, administradora de la organización racional de la vida cotidiana. La falsa idea de una teoría y práctica educativa en el pensamiento ilustrado, en donde la teoría orienta a la 
Evaluar por competencia o como potencia. Una mirada reflexiva y crítica.

práctica y a su vez, la práctica orienta a la teoría, dio origen a la idea de producción de conocimiento desde la realidad.

¿Pero de qué conocimiento hablamos y a cuál realidad nos referimos? Por supuesto, a un conocimiento elitista por cuanto separa, fragmenta a los grupos según las profesiones. Los hace clasista, sometiéndolos una realidad prefigurada, sólo alcanzable para los más aptos e intelectuales. He aquí la caracterización de una epistemología de la evaluación excluyente y bancaria, en tanto provee la discriminación jerárquica de los estudiantes en función de su nivel de eficiencia en el cumplimiento de labores determinadas por un digito cuantificable.

Las reflexiones aquí señaladas como rasgos distintivos de la racionalidad moderna y sus expresiones configurativas en la evaluación, han entrado en crisis por cuanto no encuentran asidero en la dinámica socioeducativa del mundo actual. De allí que, la crisis del gran paradigma de Occidente o del "Desarrollo", fundado en una visión tecnoinstrumental de la ciencia, está impactando fuertemente todos los espacios de legitimación de los saberes académicos instaurados durante siglos; por cuanto está en cuestionamiento su pertinencia y vigencia en los contextos pedagógicos y, por ende, en la evaluación.

\section{El monomodelo de formación y evaluación por competencia. ¿Panacea en crisis?}

La idea de progreso instaurado a finales del siglo XVIII a partir de la Revolución Industrial como bandera de verdad absoluta, el cual domina el futuro de las sociedades, en términos de Téllez (1995), ha declinado, por cuanto no hay "un principio unificador y unitario del devenir social/humano" lo cual ha hecho, “(...) Insostenible la idea de que la sociedad y los hombres avanzan inexorablemente hacia la realización de un fin: la emancipación por la razón" (p.121).

La crisis de paradigmas nos coloca ante la infranqueable necesidad de interrogarnos, de reflexionar, problematizar y replantear nuevos modos de construcción del conocimiento socio/humano. Es por ello, el intento de romper con prácticas discursivas de un monomodelo de formación y evaluación, la cual inhibe la capacidad 
crítica y reflexiva del ser en formación, para el replanteamiento y reconstrucción de criterios epistemológicos y ontológicos, dando apertura hacia una racionalidad sociocrítica. Así mismo, nos convoca a reinventar nuevas formas de relaciones, de existencia, de producción y de organización desde lo colectivo.

La pretensión aquí planteada, es impugnar el pensamiento mesiánico del positivismo, su acontecer desde la raciotécnia, en los contextos socioeducativos de Latinoamérica y, de manera particular, en Venezuela. De tal forma que, configuremos entretejidos del pensamiento crítico, los cuales franqueen todo vestigio del pensamiento racionalista de la modernidad.

Esta nueva racionalidad crítica permitirá la reconstrucción de nuevos modos de pensamiento sobre la teoría y práctica evaluativa con sentido de lo sociocontextual y humano en nuestros contextos escolares. Solo así, tendría cabida el replanteamiento de lo evaluativo desde la recuperación del sujeto sociohistórico. Es darle sentido y significado a la práctica evaluativa como proceso durante el cual, es producido la reconfiguración del sujeto sociohistórico, mediante su comprensión de los modos cómo se va constituyendo en un ser otro, en el diálogo de saberes.

No pretendemos aquí imponer un pensamiento único y totalizador, por cuanto caeríamos en las redes de lo racional, sino por el contrario ir en la búsqueda incesante, desde las contradicciones y confrontaciones generadas en el dialogo de saberes, posibilitando la reflexión, la crítica, la creatividad, del mismo modo que el compartir sensibilidades, emociones y sensaciones, transversadas en el colectivo pedagógico. Tratamos, entonces, de emprender la re-construcción de una ontoepistemología de la evaluación, la cual desde lo estético y ético; rompa con todo vestigio de la racionalidad moderna: Su práctica institucionalizada y los discursos a través de los cuales opera en los contextos escolares venezolanos. Es un intento por revertir el dominio monopolizador impuesto por algunos, quienes la denominan como lo "plus ultra" educativo: La competencia. 
Evaluar por competencia o como potencia. Una mirada reflexiva y crítica.

El término competencia fue introducido en lo educativo, por el lingüista norteamericano Noam Chomsky en 1975, para referirse a la capacidad del ser humano para aprender una lengua. El dominio (competencia) es asimilado cuando lo demostramos a través de la aplicación de un conocimiento a una situación dada. Sin embargo, dicho término según Bustamante (2010), fue tomado por Chomsky de la teoría mentalista Humboldtiana, para demostrar lo que acontece en la mente del hablante.

Posteriormente, fue utilizado por Hymes en1996, desarrollando así, la noción de competencia comunicativa pero mirada desde situaciones reales, es decir, el usuario adecua la lengua según el contexto en el cual la use (Hymes, 1996). De esta manera, introduce la acepción "competencia" en lo educativo para referirse a un "saber hacer en contexto", generalizándose la misma a todo saber programado. He allí su ineficacia sociocontextual, cuando intentamos simplificar acciones demostrativas a la generalidad de los casos, sin tomar en cuenta la reflexión sobre la acción.

El monomodelo de formación por competencia cobró fuerza en los espacios escolares y construcción de los currículos, a partir de la discusión a nivel mundial sobre cambio social, crisis educativa y demandas no atendidas, propuesto en la Conferencia realizada por la UNESCO (1994), en la ciudad de Jomtien, en el marco de acción para satisfacer las necesidades básicas de aprendizaje, producto de la necesidad de reforma educativa bajo el supuesto lema "educación para todos".

Generando con ello, una nueva panacea de la eficiencia a través de la competencia como sinónimo de calidad educativa; impulsado por demandas del mercado global capitalista. En donde los convenios internacionales para la educación; tales como el Proyecto Tuning de la Unión Europea (2001) y el Proyecto DeSeCo (2000 y 2005, Definición y Selección de Competencias) de la Organización para la Cooperación y Desarrollo Económico (OCDE), están haciendo fuerte presión para la instalación de este modelo, en todos los niveles educativos (Moreno, 2010).

Han forjado toda una parafernalia alrededor del término "competencia" cuya semántica está ligada a la noción de capital humano eficiente para el mercado global competitivo. Gimeno Sacristán (2009), da cuenta de la cerrazón preponderante hoy día, 


\section{Josefa Zabala de Alemán y José Sánchez Carreño}

Telos Vol. 21, No. 3 (2019). 544-563

en torno a este campo conceptual, la cual magnifica poderosamente sus bondades; convirtiéndolo en piedra angular de todo lo concerniente a lo educativo tanto en latinoamérica como en el mundo. $\mathrm{Y}$ ante la pregunta ¿hacia dónde nos lleva este enfoque de lo educativo?, este autor alude: "solamente un nuevo lenguaje, una jerga. Una técnica convertida en ideología fácil de echar raíces en terrenos baldíos". Y advierte en torno a la actitud asumida por el profesorado, quien "cansado de ver suceder las modas por los mismos figurantes, se quede como espectador, mudo ante este frenesí" (p. 57).

Por su parte, Pérez Gómez (2009), refiere el uso de las competencias en lo educativo como un "Saber hacer" complejo y adaptativo con base en la reflexión sobre el "Saber" como un "Querer Saber". Desde la posición de este autor las competencias superan la capacidad mecánica y reproductiva en la construcción de los saberes, aludiendo a una reflexión sobre la praxis, desde un "querer hacer" "en contextos y situaciones concretas en función de propósitos deseados" (p. 292). Posición apoyada por Martínez (2008), quien mira a las competencias como una construcción social, por cuanto nos permite ir adquiriendo los saberes, de manera paulatina, integral y compleja. Desde esta postura las competencias pasan a ser potencialidades extrínsecas e intrínsecas, las cuales el ser humano desarrolla a medida que aprende a utilizar apropiadamente en contexto, sus capacidades y habilidades cognitivas, afectivas y actitudinales.

Dentro de esta noción compleja y de desarrollo humano pretendido a favor de las competencias, la evaluación se presenta como un espacio de tensiones, en el cual es privilegiado las calificaciones con pretensión de promoción y verificación objetiva a través de un digito cuantificable. Visto así hay una desarticulación entre la teoría y la técnica (práctica), debido a la fuerte presión entre lo deseable socialmente (la certificación) y lo formativo. (Saavedra y Saavedra, 2013). 
Evaluar por competencia o como potencia. Una mirada reflexiva y crítica.

Otra mirada en torno a la máscara oculta bajo las pretensiones de una educación por competencia, es manifestada por Martínez (2009), quien hace una fuerte crítica en torno a los intereses de índole económico subyacentes en este enfoque, dado su origen, preeminentemente orientado, desde las bases de una formación de capital humano para el mercado industrializado.

Tanto el proyecto Tuning (2001) como el Proyecto DeSeCo (2005), plantean a las competencias como un "saber hacer" integrado al "aprender a aprender" complejo y adaptativo. Es decir, basado en la reflexión no solo sobre lo aprendido sino también en cómo lo aprende y lo puede aplicar en diferentes contextos (Moreno, 2010).

Pérez y Sánchez (2011) plantean que el modelo por competencias propulsado por el proyecto Tuning, nace bajo la justificación de reforma educativa y curricular para dar respuesta a las demandas económicas introducidas por la globalización. Dicho requerimiento de una educación por competencia es sustentado en la necesidad de calidad productiva para la competencia entre industrias "instaladas en el mercado" (p.146). Estos autores dicen que: "el principal cuestionamiento que se le hace a este enfoque es la adopción de una visión pragmática, reduccionista y técnica, donde la competencia queda reducida al dominio de un saber hacer procedimental" (p.146).

Por tanto, esta visión de formación por competencia está fundamentada en la instrumentalización para la capacitación de hombres insertos eficientemente en el mercado laboral. La profesionalización es el principal interés de este modelo que, de acuerdo con el cuestionamiento realizado por los autores mencionados, le imprime un matiz cosificador, alienante y deshumanizador del ser persona.

Para Barnett (2001), el modelo educativo por competencia instalado en los currículos universitarios, está centrado en la capacitación de un profesional eficaz para la industria. Este autor deja ver el control ejercido por los organismos gubernamentales y entes empresariales sobre la educación superior, imponiéndoles al enfoque por competencias como el modelo más eficaz para la formación de hombres con competencias operativas, quienes darán repuestas a los requerimientos del mercado laboral. En este entendido, lo socio histórico-contextual, tal como lo sensible y lo 
subjetivo en la formación, no tiene cabida dado que lo pretendido es, tal como lo refieren Pérez y Sánchez (2011): “dominar la realidad y no reflexionar sobre ella” (p.147). Con ello, perdemos la autonomía para reflexionar sobre el hacer educativo y formativo; dándole preeminencia a la objetivación de los saberes.

Pero ¿qué implicaciones, desde lo sociohistórico-cultural tiene este enfoque? Dara cuenta de ello o sólo es un artífice creado para la ecuménica formación de hombres máquinas, para satisfacer los intereses de la industria globalizada y competitiva. Es decir, pareciera evidenciarse una intencionalidad política y económica neoliberal solapada a merced de quienes detentan el poder para la dominación del sujetoobjetivado.

La palabra "competencia" es de carácter polisémico, tiene sus bases en la psicología conductista y en la teoría sobre el capital humano que, actualmente, está presente como la "poción curativa" para la sanación de todas las dolencias detectadas en las prácticas pedagógicas. Sin embargo, ésta pareciera carecer del sentido de participación protagónica de los actores pedagógicos y de la reflexión en torno a los procesos culturales e históricos involucrados en dichas prácticas (Torres Jurjo, 2009).

Por lo cual, consideramos es cuesta arriba poder comprenderla desde nociones, las cuales convoquen a la formación desde lo humano, desde la subjetividad del ser como persona pensante, en su relación consigo mismo y mediado por el mundo, donde esté inmerso. Al respecto, Alfonzo, Curcu y Pérez (2009), manifiestan: “la concepción de competencias, de cómo "saber hacer con el saber", remite la discusión a una determinada forma de saber y a un saber especifico que la evaluación tradicional erige como objetividad y, por tanto, como lo válido del proceso educativo" (p.30). De esta manera, insisten estos autores en "la enseñanza por competencia acentúa el concepto de performatividad" (p.30), que, entendido como reproducción de saberes, es una representación de la razón instrumental. 
Evaluar por competencia o como potencia. Una mirada reflexiva y crítica.

Desde este abanico de referencias teóricas, la noción de formación por competencias tiene fuertes incongruencias de orden epistemológico, axiológico y praxiológico, por lo tanto, siguiendo a Álvarez Méndez (2005), en la práctica, el discurso de las competencias refuerza la importancia de los métodos basándose en un "saber hacer cómo". Es decir, está enfatizado en un saber hacer funcional, en el cual operacionaliza (segmentan) las actividades a ser realizadas por el educando.

La evaluación es reducida a un mero procedimiento técnico para el control de la calidad educativa, sin tomar en cuenta a los involucrados y al contexto donde estén inmersos. Por ello, terminará reducida a la calificación, jerarquización y promoción; según estándares nocionales, los cuales convocan a la demostración de capacidades como actividad de logro.

Difiriendo del modelo por competencia, propuesto por el proyecto Tuning y DeSeCO para la formación de profesionales competitivos y competentes, a ser constituidos en guardianes eficaces de un mercado globalizado, Pérez y Sánchez (2011), opinan que:

El cinismo de un currículo por competencias con apropiación del sistema categorial de la complejidad y la transdisciplinaridad no hace sino ocultar el enfoque positivista que le da origen, ya que se fundamenta en modos de agenciamiento que castran las potencialidades subjetivas de reflexión, interpretación, comprensión, complejización y pensamiento crítico liberador. (p.150).

De acuerdo con Del Rey (2012), el modelo por competencia deriva de tres momentos coyunturales en lo educativo. En primer lugar, la creación de la Asociación para la Evaluación de Resultados Escolares y la Propuesta Taxonómica para la Redacción de Objetivos de Benjamin Bloom. De esta manera, nace la evaluación por estándares nocionales finalistas, cuyo soporte instrumental eran las pruebas estandarizadas. Luego, en segundo lugar, con la perspectiva administrativa científica sobre el trabajo de Frederick Taylor, entroniza la medición en las prácticas evaluativas, con base en los resultados, siguiendo los preceptos de eficacia y eficiencia abonados desde las producciones industriales. El último y tercer momento, lo viene a constituir la 
propuesta curricular de Ralph Tyler (1986), quien presenta una extensión de los objetivos de la enseñanza basados en la medición y la calificación.

A partir de entonces, la educación es asumida como rentabilidad para el Estado, por cuanto es vista como una inversión en el capital humano necesario para el progreso de las naciones. Las competencias por ser no solo conocimientos sino también uso y aplicación en contextos determinados, fue acuñada como política educativa por "su flexibilidad y adaptabilidad a las situaciones sociales cambiantes, así como a la proyección continua de aprendizaje que, en este nuevo orden, implica la cualificación constante y la inversión en el capital humano propio" (Saavedra y Saavedra, 2014:7374).

El modelo de educación por competencia, con sus diferentes acepciones, ha imperado en los contextos escolares; sosteniendo una manera racional de formación, la cual hace de la práctica pedagógica $\mathrm{y}$, por ende, evaluativa una actividad descontextualizada, fragmentada y objetiva. Ésta tiene por finalidad la unilinealidad cognitiva del educando. Por lo tanto, en vez de formación es adiestramiento; es decir, disciplina al educando haciendo de éste un clon en serie, desprovisto de libertad para discernir, reflexionar y divergir sobre su propio aprendizaje; convirtiéndolo en aquello referido por Foucault (1991) como "un cuerpo dócil".

Moreno y Soto (2005), en sus reflexiones en torno al enfoque del monomodelo por competencias, deja explicito el ambiente asfixiante y cerrado en el que éste opera, por cuanto su implementación en vez de dar soluciones a las ineficiencias e inequidades del sistema educativo y a sus carencias formativas, tiende a incrementarlas, al consolidar la condición postmoderna mercantilista en la educación, es decir, al no atender a las necesidades reales y sentidas por los educandos, incrementa “ el gran malestar que sienten niños, adolescentes y jóvenes sobre una educación que nos les dice nada sobre los problemas de sus vidas, el mundo, el universo, (...),el sentido de la vida, etcétera.(p. 79). 
Evaluar por competencia o como potencia. Una mirada reflexiva y crítica.

Sin embargo, a pesar de los muchos detractores y limitantes sobre las competencias en educación hay quienes abogan por ella, desde una mirada de lo humano, así De zubiría (2006), manifiesta que se debe desligar a las competencias de nociones que la enmarcan dentro de lo técnico industrial para mirarla desde una visión del desarrollo humano. De esta manera, manifiesta el autor (2006). "Las competencias deben ser entendidas hoy en día como aprehendizajes integrales de carácter general y las cuales se expresan en multiplicidad de situaciones y contextos". (p. 24).

Tobón (2008) por su parte, apuesta por una formación basada en competencias desde lo complejo y humano, resemantizando su noción en base a una postura crítica, en la cual se integra el saber ser, el saber conocer y el saber hacer. De allí que este autor (op cit) la defina como "una compleja estructura de atributos necesarios para el desempeño en situaciones diversas donde se combinan conocimientos, actitudes, valores y habilidades con las tareas que se tienen que desempeñar en determinadas situaciones". (p.47).

En suma, los intentos por resignificar el concepto por competencia quedan entrampados en la unilinealidad y homogenización de un saber hacer funcional, objetivo y deshumanizante, debido a no dar cuenta de la potencialidad reflexiva critica del ser humano, sobre su formación y de la realidad sociocontextual e histórica en la cual está inmerso. A través de nuevas teorías onto-epistemológicas se ha intentado enmascarar la verdadera pretensión de una formación y evaluación por competencias, la cual no es más, tal como lo refieren Pérez y Sánchez (2011), “conformar un estudiante acrítico, zoologizado, individualista, lo que, indudablemente genera un profesional no comprometido, encasillado, reproductor, experto". (p.149). Desde el enfoque por competencia parece poco probable vislumbrar una evaluación sociocontextual e intersubjetiva, capaz de generar espacios para lo sensible, lo ético y lo estético en la formación, dada su naturaleza mecanicista y de control.

En tal sentido, necesitamos avizorar nuevos sentidos y miradas para una ontoepistemología otra de la evaluación. Por ello, es prioritario ir tras la búsqueda de nuevas 
líneas de fuga en torno a la evaluación, como espacio para la potenciación del ser persona.

\section{La evaluación como potencia del ser persona}

En la actividad educativa hay un poder instituyente e impuesto como fuerza disciplinante. Al respecto Foucault (1990) citando a Walhausen, expresa: "el poder disciplinario, en efecto, es un poder que, en lugar de sacar y de retirar, tiene como función principal la de "enderezar conductas" (p.175). La evaluación por competencia entonces, entendida como actividad disciplinante es asumida como medio de control, suprimiendo todo poder emancipador en quien es evaluado, mientras quien ejerce la función evaluadora es convertido en el ejecutor o agente de la acción de dominación; siendo también, al mismo tiempo, un sujeto dominado.

Vislumbramos, entonces, una reforma del pensamiento para ir más allá de los límites de la simpleza y al rescate lo subjetivo e intersubjetivo, desplegada en la vida sociocultural del ser humano. Esto ha permitido la re-configuración de los modos en los cuales nos apropiamos y valoramos la realidad, la cual nos embulle y re-edifica, en tanto somos seres, quienes a través de la comprehensión interpretativa sobre quiénes somos y hasta dónde podemos llegar, tenemos la potencialidad de releer, y redescubrir nuestro mundo de vida. Urge, entonces, la necesidad de rescatar lo ético y lo estético en el evaluar. Es decir, una evaluación armonizadora de lo sensible, lo creativo y lo autónomo, intrínseco en la formación y de este modo, resurja como potencia emancipadora y vitalista del ser persona.

Esto implica en términos de Téllez (1998), ir en busca de nuevas sensibilidades, nuevos horizontes, realidades utópicas para el rescate del sujeto sensible, quien aprecia, valora, crea, comprende su propia existencia y la de los otros, desde la realidad en la cual está inmerso. Un sujeto "otro" capaz de desprenderse del "ello" freudiano para 
Evaluar por competencia o como potencia. Una mirada reflexiva y crítica.

poder llegar al "nosotros" desde el Yo foucaultiano. Como dicen Deleuze y Guattari (1999): "Yo es Otro porque es hecho otro por los otros, y recíprocamente" (p.220).

Esta nueva noción ontológica de ser, está enmarca en una visión del ser humano, quien es capaz de reconocerse a sí mismo desde la libertad de interpretar-se e interpretar a los otros. Un sujeto espiritual, sensible, creativo y consciente de quien es él en sí mismo, reconociéndose uno y múltiple a la vez, por la acción de los otros en él y de él en los otros. Así entendido, este sujeto va constituyéndose desde la inmediatez de las experiencias vividas con los otros y con su otro.

Es reinterpretarse como ser con identidad desde la alteridad como el "yo otro" constituido por la complementariedad. Es el gusto por la libertad, la cual nos posibilita una manera otra de entendernos a nosotros mismos, a los "otros", para desamarrarnos de falsas ideas instituidas, de acuerdo con los intereses políticos e ideológicos de un orden social imperante.

Derivado de lo antes expuesto, la evaluación no puede pensarse como un simple acto para calificar o comprobar conocimientos; por lo contrario, ésta trasciende sustantivamente, al ser relacionada con ser-hacer-sentir-convivir del humano. Es decir, es asumida como acción para la comprensión, reflexión e interpretación de la realidad, en la cual están inmersos los sujetos educativos. Un espacio donde a través de los distintos modos de comunicación generados en el aula y fuera de ésta, emerjan nuevos aprendizajes compartidos y reinterpretados en el diálogo intersubjetivo.

Esta noción sobre la evaluación calza perfectamente con lo expuesto por la UNESCO (2008), sobre generar un aprendizaje para el emprendimiento, mirado desde el ser-conocer-hacer-convivir, donde la evaluación jugará un papel reflexivo y orientador de las acciones pedagógicas en su devenir. Esta provocará momentos para que, tal como lo refiere Jaimes (2018: s/p), los involucrados en la acción educativa aprendan a:

- Aprender a ser, su meta es lograr que el educando comience a reconocerse, a estimarse, a identificar sus potencialidades y comience a utilizarlas al máximo para superar cualquier debilidad o carencia. También aspira a que aprecie sus preferencias y las desarrolle, aprenda a desenvolverse socialmente y a practicar la convivencia 
democrática, comprendiendo que sus derechos son los mismos de sus iguales y que tiene deberes que cumplir comenzando con el propio.

- $\quad$ Aprender a conocer, que supone la adquisición de herramientas básicas para la construcción de conocimientos, la comprensión del medio y poder comunicarse, aunado al desarrollo de la creatividad, la curiosidad y el sentido crítico.

Aprender a hacer, implica el desarrollo habilidades y la utilización de herramientas requeridas para la aplicación de procesos del pensamiento, experiencias y conocimientos a situaciones socio-educativas.

- $\quad$ Aprender a convivir, supone la adquisición de habilidades para participar y cooperar, su desarrollo exige preparar el estudiante para que se identifique consigo mismo y con su grupo de pares, sepa dialogar y negociar, manteniendo relaciones interpersonales armónicas.

Esta nueva mirada entorno a la evaluación, empodera al educando, lo potencia, al formar parte de su proceso de aprendizaje; por cuanto participa de su acción formativa. La evaluación permitirá entonces, la concienciación de la relación vida- mundo educativo -experiencia para la emergencia de nuevos modos de construcción pedagógica en colectivo. Así, los proyectos de aula dejarán de ser ficticios o como algunos refieren Disneylatinizados, sino más bien, productos de las realidades sentidas $\mathrm{y}$ vividas por el colectivo comunal-educativo.

Ahora bien, ¿cómo deslastrarnos de una evaluación enajenada de lo humano a través de la competencia para vislumbrar una epistemología evaluativa otra?, para ir tras la búsqueda de una evaluación orientada hacia la potenciación del ser persona, como aquel en permanente constitución de su ser, desde la alteridad, "el ser con el otro" y durante el diálogo deje emerger y comparta lo subjetivo, como expresión de la intersubjetividad.

Planteamos una evaluación como potencia del ser persona, por cuanto le permite desarrollar sus cualidades y a la vez, aprender otras nuevas. Pretendemos entonces, 
Evaluar por competencia o como potencia. Una mirada reflexiva y crítica.

desde esta nueva perspectiva del evaluar, sustentada en lo ético y estético, propiciar una formación de lo humano del ser humano. De allí que, ésta sea entendida como un espacio para la liberación reflexiva y critica sobre cómo, qué y para qué aprendemos a aprender y reaprender con los otros, en el contexto escolar.

La evaluación como potencia, les permitirá a los seres en formación, empoderarse de sus potencialidades, haciéndose conscientes de su capacidad de transformar-se, en la medida como vayan constituyéndose en seres libres para hacerlo. En consonancia con ello Freire (2006), en sus planteamientos avizora una educación como la puerta para acceder a la libertad, por cuanto facilita "la reflexión sobre su propio poder de reflexionar" (p.34). Atendiendo a lo dicho, crearemos los espacios donde el educando esté consciente de sus potencialidades y acceda a ellas en función de mejorar su proceso formativo. Tal como como lo señalan Jaimes (2018), debemos:

(...) canalizar y potenciar el desarrollo de los sujetos que participan en ese proceso socio-histórico y educativo. Se pretende que las y los estudiantes participen activamente en el logro de los fines propuestos y que avancen tomando en cuenta sus potencialidades, capacidades y habilidades para aprender (s/p).

La evaluación entonces, proveerá al educando de los espacios necesarios para la reflexión crítica sobre cómo, por qué y para qué aprende. De igual manera, dará apertura a nuevas experiencias compartidas, las cuales lo sensibilizan ante la acción de los otros que, como él, están empoderándose de nuevos modos estratégicos para la reconstrucción de los saberes, de esta manera, aprenden en comunión a ser corresponsables de su propio aprendizaje.

\section{Conclusión}

La educación en la actualidad nos conmina a estar en permanente revisión prospectiva del hacer pedagógico, debido a los cambios transcendentales en la ciencia, la tecnología, lo político y lo sociohistórico-cultural, los cuales demandan una nueva mirada de la formación del hombre y de su participación en los procesos de 
transformación social. Por ello, no podemos anclarnos a viejos paradigmas y seguir como si todo estuviera igual. En tanto, no lo es. He allí la debilidad, la cual corroe día a día la práctica evaluativa en nuestros contextos educativos.

Todavía estamos atados a un magma petrificado del proceso evaluativo, haciéndolo infructuoso y alejado de la realidad socioeducativa. La evaluación por competencias es el ardid conceptual y procedimental acogido hasta ahora para estimar la acción educativa en el aula, pero su gran limitación está en su génesis conductistainstrumental. Por lo tanto, aun cuando quieran hacer de ella una acción reivindicadora de lo humano en la formación, sigue entrampada en su modelo de origen. Sin embargo, no podemos dejar de valorar sus bondades, las cuales explicitan su intencionalidad: la cualificación del capital humano requerido para el mercado global.

Empero, las nuevas emergencias societales aluden por una educación, la cual no solo prepare técnicamente el profesional requerido, sino que además, le permita transformarse como un ser humano más humano. Allí entra en juego lo sensible, lo ético y lo estético. Debemos entonces, crear los espacios para el fortalecimiento de lo subjetivo en la formación. Necesitamos de un profesional crítico, reflexivo, creativo, transformado; capaz de valorar su entorno, sentir con el otro y reinventar la vida en colectivo.

De allí que, la evaluación no puede seguir como práctica para la comprobación de conocimientos ni para valorar competencias adquiridas. Deberá ser asumida como un proceso de comprensión y reflexión crítica compartida para la potenciación de la comunidad pedagógica. De esta manera, ésta irá dando visos de cómo aprender a aprender, potenciando nuestras capacidades, habilidades y sentires como ser persona. Así, aprenderemos a reinventar y valorar el acontecer de la vida socioeducativa para su transformación y mejoramiento en colectivo.

\section{Referencias Bibliográficas}

Alfonzo, Norys, Curcu, Antonio y Pérez, Enrique (2009) Para Conceptualizar a la Evaluación desde el Vínculo Formación Subjetividad. Revista 
Evaluar por competencia o como potencia. Una mirada reflexiva y crítica.

Evaluación y pedagogía en tiempos de cambio. № 1 Venezuela. (Pp. 19-33).

Álvarez Méndez, Juan (2005). Evaluar para conocer, examinar para excluir. Morata. España.

Barnett, Ronald (2001). Los límites de la Competencia. El conocimiento, la educación superior y la sociedad. Gedisa. España.

Bustamante, Guillermo (2010) Competencia lingüística y educación. Extraído de http://www.redalyc.org/articulo.oa?id=345932034006 Consulta: 15/04/ 17.

Damiani, Luis (2009). Epistemología y Ciencia en la Modernidad. Ediciones FACES. UCV. Venezuela.

Deleuze, Gilles y Guattari, Félix (1999) Mil Mesetas: Capitalismo y esquizofrenia. Editorial Pre-Texto. España.

Del Rey, Angélique (2012). Las Competencias en la Escuela. Una visión crítica sobre el rendimiento escolar. Paidós. Argentina.

De Zubiría, Julián (2006). ¿Qué son las competencias? Una mirada desde el desarrollo humano. Extraído de: https://www.academia.edu/17593400/Que-son-lascompetencias Consulta: 30/04/19.

Freire, Paulo (2006). Pedagogía de la autonomía. Siglo Veintiuno Editores. México.

Foucault, Michel (1990). Tecnologías del YO. Paidós Ibérica. España.

Foucault, Michel (1991). Vigilar y Castigar. Siglo XXI. México.

Gimeno Sacristán, José. (2009). Educar por Competencias. ¿Qué hay de nuevo? Morata. España.

Hymes, Dell (1996). Acerca de la competencia comunicativa. Traducido por: Gómez, Juan. Extraído de: https://revistas.unal.edu.co/index.php/formayfuncion/article/view/1705/1790 Consulta: 10/05/17

Jaimes, Jaime (2018). La Potencia como noción filosófico-pedagógica para una formación humanista. IV seminario Internacional de Arte, Amor $\quad$ y Filosofía. U.C.V. Venezuela.

Martínez, Héctor (2008). El enfoque por competencias desde la perspectiva del desarrollo humano. Aspectos básicos y diseño curricular. Extraído de: http://www.unife.edu.pe/publicaciones/revistas/psicologia/2013/9 martinez.p df Consulta: 28/04/19.

Martínez, Juan (2009). La ciudad se convierte en competencia: Avances y retrocesos. En: Sacristán, Jimeno (compilador). Educar por Competencias ¿Qué hay de nuevo? Morata. España.

Moreno, Tiburcio (2010). Competencias en educación superior: un alto en el camino para revisar la ruta de viaje. Revista Perfiles Educativos. $\quad \mathrm{N}^{\circ} 124$. Venezuela. (Pp. 69-92).

Moreno, Prudenciano y Soto, Graciela (2005). Una mirada reflexiva crítica al enfoque por competencias. Extraído de: 
http://www.quadernsdigitals.net/datos/hemeroteca/r_24/nr_729/a_9917/9917. pdf Consulta: 02/05/19.

Pérez Gómez, Ángel (2009). ¿Competencias o pensamiento práctico? La construcción de los significados de representación y de acción. En: Sacristán, Jimeno (compilador). Educar por Competencias ¿Qué hay de nuevo? Morata. España.

Pérez, Carlos y Sánchez, José (2011). Hacia un currículo transdisciplinario: una mirada desde el pensamiento complejo. Revista de Teoría y Didáctica de las Ciencia Sociales. N ${ }^{\circ} 17$. Venezuela. (Pp. 143-164).

Saavedra, Liliana y Saavedra, Sneider (2014). Evaluación por contextos de origen y contradicciones pedagógicas. Revista Itinerario Educativo. No 64. Venezuela. (Pp.65-78).

Téllez, Magaldy (1995). Crisis de paradigmas en las ciencias sociales. competencias: de Clausura. Signos de invención. Revista Latinoamericana de Estudios Avanzados. $\mathrm{N}^{\mathrm{o}}$ 0.Venezuela. (Pp. 110-131).

Téllez, Magaldy (1998). Desde la alteridad: Notas para pensar la educación de otro modo. Revista Latinoamericana de Estudios Avanzados. $\quad N^{\circ} 5$. Venezuela. (Pp. 119-145).

Torres, Jurjo (2009). Obviando el debate sobre la cultura en el sistema educativo: Cómo ser competentes sin conocimientos. En: Sacristán, Jimeno (compilador.) Educar por Competencias ¿Qué hay de nuevo? Morata. España.

Tobón, Sergio. (2008). Formación basada en competencias. ECOE. Colombia. Tyler, Ralph (1986). Principios básicos del currículo. Troquel. Argentina. UNESCO (1994). Declaración mundial sobre educación para todos. Extraído de: http://www.unesco.org/education/pdf/JOMTIE_S.PDF Consulta: 16/ 03/17 UNESCO (2008). Conferencia Regional de educación superior de América Latina y el Caribe. Mimeo. Colombia. 